\title{
Application of Ceramic Materials in Modern Urban Sculpture
}

\author{
Maomao Liu ${ }^{1, a}$ \\ ${ }^{1}$ School of Ceramic Art, Jingdezhen Ceramic Institute, Jingdezhen, China \\ a46717203@qq.com
}

Keywords: Ceramic materials, Modern urban sculpture, Public art

\begin{abstract}
As a very special material, ceramics are increasingly favored by sculpture artists and attracting more and more attention of the public. The paper analyzes the characteristics of the ceramic materials, such as naturality, strong flexibility and strong tranfomative quality etc. Through the description of the types of the ceramic materials and then illuminates the advantages of ceramic materials involved in modern urban sculpture and its application technique in modern urban sculpture to provide a basis for the ceramic art walking into the public space.
\end{abstract}

\section{Introduction}

The development of social science and technology promotes the public art to develop in diversify directions. The artists are no longer just concerned about the factors such as craftsmanship, theme, form and so on about the sculpture but they are paying more attention on the application of materials. They also have the creative try on the work effect brought by the materials. The ceramic materials are rich in characteristics which gathered the human emotions and the original nature of the soil and its application in the modern urban sculpture can pursuit the combination with the feeling of the new art to a large extent. Today, more and more sculptors began to pay attention to the application of ceramic materials in the works.

\section{The Type of Ceramic Materials}

The ceramic materials mainly follow the division of the traditional ceramics to be divided into pottery, stoneware and porcelain if divided according to the material, firing temperature. Pottery has thousands of years of heritage context without glazed surface and with high iron content in the casing and low firing temperature which is generally about $800{ }^{\circ} \mathrm{C}-1000{ }^{\circ} \mathrm{C}$ and its texture is loose with poor density and high water permeability. The stoneware was later than the pottery which is a kind of ceramic like both pottery and porcelain and its firing temperature today can be increased to $1000{ }^{\circ} \mathrm{C}-1200{ }^{\circ} \mathrm{C}$ or so with more compact casing to lower the water permeability. The material of porcelain has been composed by the materials such as porcelain, kaolin, quartz stone, mullite and so on and there are vitreous enamels or painted in the surface. The porcelain shall be fired in the kiln through high temperature (about $1280{ }^{\circ} \mathrm{C}-1400{ }^{\circ} \mathrm{C}$ ) and the glazing color on the porcelain surface will have different chemical changes due to the different temperature. So the application is relatively extensive.

\section{The Characteristics of Ceramic Materials}

The application of the ceramic materials in the urban sculpture is increasing and it has the characteristics of naturality, strong flexibility and tranfomative quality.

\subsection{Naturality}

As the saying goes "A side water and soil, raises a party person." The ceramic made from the soil exudes a natural and simple temperament and has the incomparable natural characteristics compared to other many other materials. The ceramic materials are originating from nature and the soil and water are the bounty from the nature. And the people have a natural affinity for the soil and 
express their deep affection spontaneously. Any people can show their emotion through the expression their views on the soil materials, which is originated from the people's inherent natural talent of the soil.

\subsection{Strong Flexibility}

The forming process of ceramic materials makes it has the characteristic of strong flexibility. The appropriate amount of water should be added in the clay before the firing of the ceramic materials then the clay was balled up to the clay ball. So the clay can change in form under the human forces. And the nature of the clay will still be maintained when the external forces stop, which make the ceramic materials can be made into kaleidoscopic shapes according to the need of the works.

\subsection{Tranfomative Quality}

The briquette with the nature of the natural material has qualitative changes after the calcination and can be converted into artificial implements with the feature of high temperature resistance, decay resistance and hard texture. That why the people invented the pottery with the integration and control of other factors and expanded and improved it gradually. It has the excellent characters of the materials such as hard texture, high temperature resistance, no oxidization, no decomposition, no deformation, no discoloration, easy to clean etc. coupled with the extremely abundant glazing colors, mysterious kiln changes, make people produce natural intimacy. Compared to the expensive materials such as bronze, Granite, marble and so on, the ceramic is the relatively cheap with high intensity, which is the economical, stable material with good effect.

\section{The Advantages of The Ceramic Materials to Be Involved in Modern Urban Sculpture}

Firstly, the ceramic is made of thousand degrees of high temperature and has the advantages of wear resistance, corrosion resistance, high strength and durability. The ceramic sculpture works will not fade after being placed in the city public space for a long time and its storage time is very long, which has provided the conditions for the application in the urban public space. In view of the effect of firing, the surface of the clay is rough with strong water absorption due to its original and natural characteristics and its works has the gorgeous straightforward and artistic characteristics; The briquette surface of the petuntse is relatively smooth after the refining and is suitable for a variety of glaze decoration. The fired works has the fine and elegant artistic features. It is just because the ceramic material has the features of hard texture, high temperature resistance, water erosion resistance, not easily weathered showing the unique and strong advantages compared to the materials such as metal, resin, wood, glass and so on and has become one of the ideal material for the public art.

Secondly, the ceramic art has formed the unique artistic language and aesthetic form after thousands of years of development. The modern pottery focuses on the search and experiment of their own media characteristics and fully embodies the essence of pottery language: intrinsic beauty value of mud, glaze, and fire. The effect of the ceramic sculpture placed in the public environment is to beautify the environment, improve the artistic quality of the urban environment and the aesthetic taste of the public. The various processing of the ceramic clay during the creation can produce different forms and texture beauty, while the glaze will show different texture and color. Due to various reasons such as level of attainment, temperature, firing time and so on. The ceramic decoration can be divided into underglaze enamel, blue-and-white and inlaid decoration, etc., which enriched the visual vocabulary of the ceramic greatly.

In addition, the ceramic material is the art of the integration of water and fire, and the water, fire and soil used for the preparation of ceramic materials are closely related to human life. The ceramic can give us a kind of inaccessible sense of intimacy. The texture presented by the ceramic material through the deployment of water and smelting of fire make the people has the desire to be close to it. So the ceramic products become a natural link between man and the environment, and the ceramic sculpture is the art form with the cultural symbol which has a kind of special emotional 
representation, which is close to nature, close to the public, and integrated with the environment.

\section{Application of Ceramic Materials in Modern Urban Sculpture}

\subsection{The Direct Use of Ceramic Materials}

As the ceramic material has the incomparable advantages which the other materials did not have, they can be used directly in the sculpture. The clay sculpture language, glazing color and the sense of beauty after the firing of the ceramic cannot be replaced by other materials. For the sculptor, each material has its own aesthetic characteristics which can be used as the design language to convey the artist's design ideas and emotions. The ceramics is the relatively common outdoor sculpture material and its application plays a positive role to break through the traditional outdoor sculpture model, which meet the needs of the creator directly. The most prominent effect in urban sculpture is the beauty of the material, and the ceramic materials is one of the best. In the previous public art sculpture, the artists are mainly used the traditional materials such as stone and copper etc., but the application of the sculpture materials for the artists now has broken through the traditional materials such as metal, plastic, stone, fiber, tempered glass and so on. However, they chose the new materials such as ceramics. The ceramics combines many advantages together. The nature of the soil, the natural texture, fire molding, the fragrance of the soil, can call the ancient memories, and achieve the dream of people to be closer with the nature and the environmental protection of the ceramics material is universally accepted. For example, the two symbol sculptures in Jingdezhen-the Porcelain Capital "soaring(Ang)" (Figure 1)and "Ascension(Shengteng)" (Figure 2)located in Jinling Avenue of Jindezhen with 12 meters in height. The "soaring(Ang)" which symbolizes the ceramic was designed with the "H" -type frame structure and was created by the engraving and mold pressing process with the absorption of the creation method of printed pottery. It was glazed with warm-toned high temperature colored glaze and presents a variety of texture level. It was highlight with colors and was in stark contrast with the surrounding color environment, which is easy to leave a deeper impression on the audience; The "Ascension(Shengteng)" was in shape of blue and white porcelain and the decoration was the decorative patterns, showing the characteristics of Jingdezhen-the Porcelain Capital.

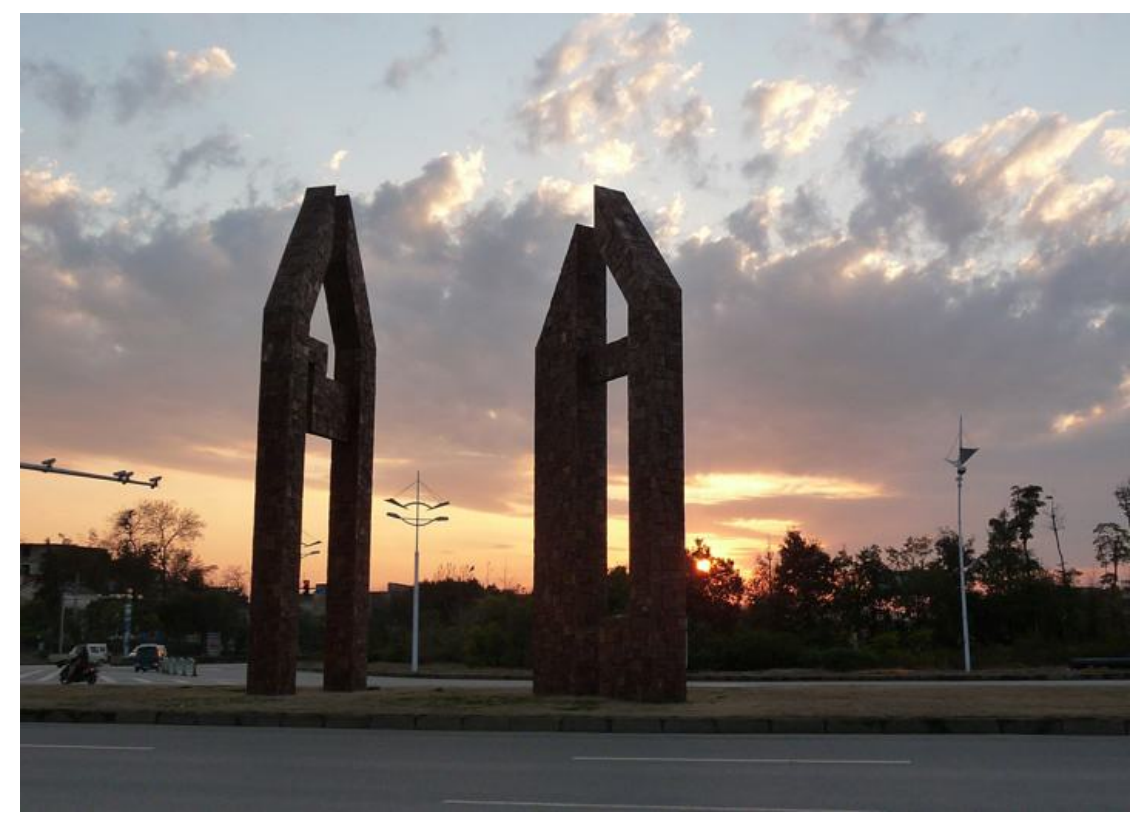

Figure 1 The ceramic sculpture "soaring(Ang)" in Jingdezhen. 


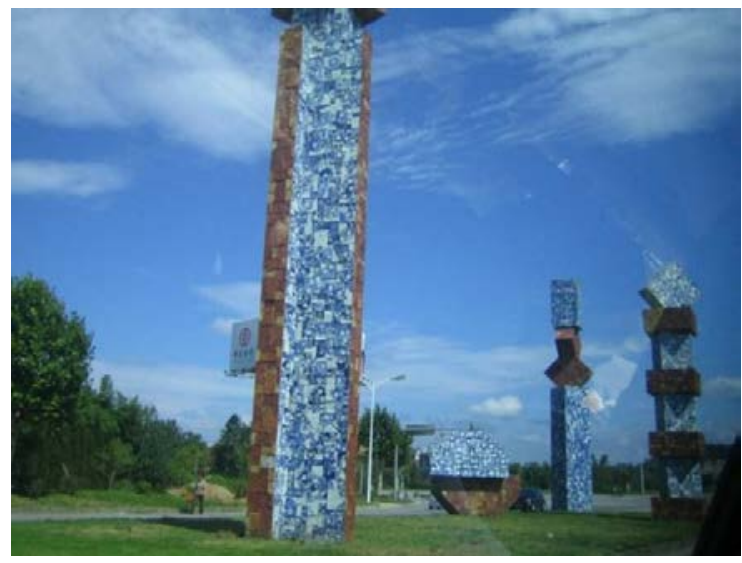

Figure 2 The Ceramic sculpture "Ascension(Shengteng)" in Jingdezhen

\subsection{The Combining Application of Ceramic Materials with Other Materials}

The vast nature provides us with a wealth of materials, such as stone, wood, earth, metal, etc and each material itself has a specific veins, color, and texture, with unique material language. Adding the integrated materials in the modern pottery can enrich the creation of the material language of the ceramics and break through the unicity of the traditional ceramic material types. The original properties of the ceramic material can be changed through adding heterogeneous material to the clay or adding heterogeneous material to the modern ceramic sculpture to make it have more abundant visual effect and enrich the expression of ceramic material, giving people a kind of the unique beauty.

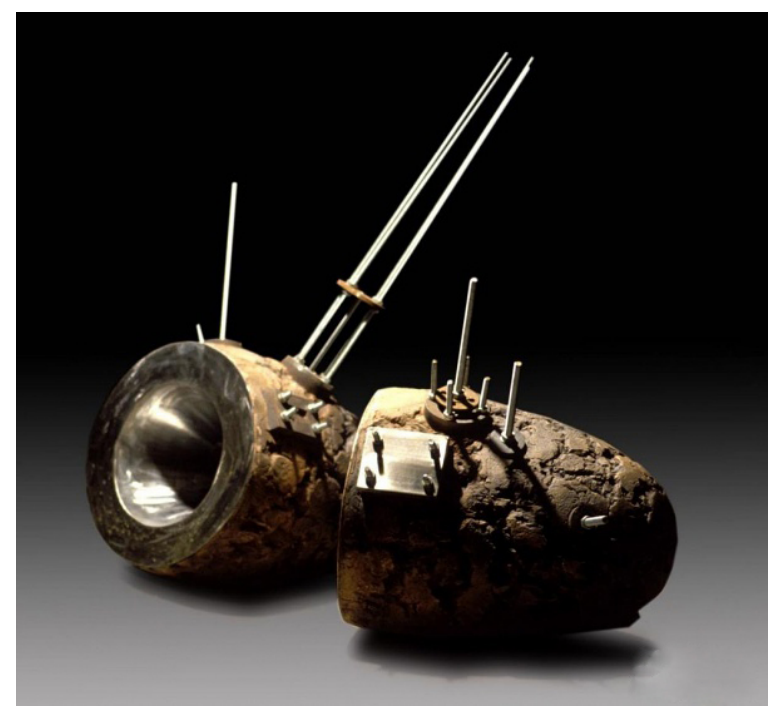

Figure 3 The work of “The space program” by Lu Pinchang.

In addition, the ceramic sculpture itself has the fragile characteristics and they are more easy to be deformed in the firing and production. Especially the ceramic sculpture with larger size and the entire production process is very complex, which need to be jointed after the single firing of each part. Just because the limitations of ceramics that the ceramic materials can be combined with other materials, which is more obvious especially in the outdoor ceramic sculpture and large ceramic sculpture. The non-ceramic materials can play a role to connect the other parts in the ceramic works and have the organic combination between the ceramic works in the same time. The artists can express their emotions with the characteristics of different materials. For example, American artist Christina Potwell, who specializes in the use of the material such as glass, metal lattice, fiber and wax etc. to combine with the ceramic materials and make the ceramic material filled with magical expression through a special combination of ways and firing method. And at the same time, this has given mysterious color to her works and the texture beauty is very prominent in her works. As shown in figure 3, pottery artist Lu Pinchang in China: in his work Space Program, he combined the 
metal and ceramics and has showed the charm of art in the form of novel sculpture art.

\section{Conclusion}

Ceramic materials involve in the urban sculpture creation from the production of daily necessities and works of art and walk to the outdoor space from the original indoor daily necessities, decorations. They have not only enriched the modern ceramic art form, but also expanded the design ideas of public art. Some of the current ceramic sculpture has integrated with other new materials in the materials and has expanded the scope of application of ceramics, which has enhanced the ceramic bearing of the public art. China's modern ceramic art should participate in the construction of contemporary global culture and achieve the communication of their own form relying on its own advantages.

\section{References}

[1] Xiao'ai Yin. A Brief Analysis on Ceramic Sculpture Going Outdoors. China Ceramics, 2003(4), 58-59.

[2] Zhiqi Liu. Study on the Application of Ceramic Materials in Environmental Sculpture. Art Education Research, 2015(8),44.

[3] Qimei Luo. The Artistic Language of Ceramic Sculpture. Art Science and Technology, 2015(4), 124.

[4] Zejia Zhang, Zhenyu Fu. Discussion on the Functions Of Sculpture In Contemporary Public Art. Journal of Changchun University, 2009(7), 102-103.

[5] Dan Chen, Fangyu Meng. Study on Application of Materials in Urban Sculpture. Modern Gardens, 2006(8), 13-16. 